\title{
EXPLORING THE ROLE OF SCIENCE AND POWER RELATIONS IN TOURISM STUDIES: AN INTRODUCTION TO THE SPECIAL ISSUE
}

\author{
RAMI K. ISAAC AND ERDIN AKMAK \\ Academy for Tourism, NHTV Breda University of Applied Sciences, Breda, The Netherlands
}

This special issue of Tourism, Culture \& Communication on "Tourism and Power: Science, Culture, and Society" advances theoretical, conceptual, and empirical research on power relations in the context of tourism. The call for papers was inspired by our theoretical and research interests in science and power relations in tourism studies based upon a session organized by the Research Committee 50 (RC50) on International Tourism, of the International Sociologist Association (ISA) congress in Yokohama, July 2014.

The collection of articles in this special issue provides original and innovative international tourism research studies that are embedded with interdisciplinary and transdisciplinary theoretical, conceptual, and methodological thought in the study of tourism and power relations. This special issue is a collection of articles representing authors from the UK, China, India, Pakistan, Bulgaria, Palestine, and Turkey.

The role of science, culture, and society was without question a broad and exciting line of inquiry within tourism studies. Science has been depicted a very long time as an isolated phenomenon (Lakatos \& Musgrave, 1970; Popper, 1963) that is driven forwards by internal mechanisms. Scientific progress has been imagined as a self-corrective development steered by an internal criterion like testability or falsifiability. According to Popper (1972), scientific objectivity refers to the scientific method and not to the individual or group consciousness. Science has its own logical structure, which has to be distinguished from its social backgrounds and circumstances. In this sense, Kuhn (1962) opposes Popper, where he argues that the choices between scientific theories can only be understood by referring to these social and psychological backgrounds. In the last two decades, this image has become more relative through the acceptance of external development codeterminant for scientific development (Kuhn, 1962). Yet science is an embedded phenomenon that is always heavily influenced by the surrounding environment. This makes us sensitive to the political, economic, sociocultural, and technological influences on scientific developments. When a situation transits from former to an alternate one, the paradigm revises its view of the field, its methods, and objectives. Sometimes this revision becomes dramatic and the paradigm becomes a totally new one. This is called "paradigm shift" and argues that no two paradigms are identical. Each of them has its assumptions, laws, definitions, and methods. According to Kuhn, paradigm shifts constitute a "gestalt switch." This means one's mind needs to switch from the one to the other to see the one and the other. Other scholars such as Foucault (1966) introduced a more nuanced picture of how fields of knowledge and power change. 
This certainly goes for the tourism field of social scientific research (Tribe, 2006). Especially, power relations have been emphasized in epistemological discussions. For example, postcolonialism is one of the most interesting debates that was focusing on these power relations worldwide. In order to have an understanding of postcolonialism, we first need to get some insights about Eurocentrism. In recent years, Eurocentrism (Isaac, 2016) became a major intellectual and political concept (Wallerstein, 1997). The term Eurocentrism was coined during the period of decolonization. Following World War II, the term was based on an earlier adjective Europe-centric approach, which came into use in the early 20th century. The term appears in precisely this form in the writings of the right-wing German writer Karl Haushofer during the 1920s (Jorn, 2004). There has been a development and shift in terminology related to the shifting power in the world from Europeanization to Americanization and to globalization. In line with this development, "Eurocentrism” became less popular as a concept. Following the publication of Edward Said's Orientalism (1978) and the rise of postcolonial theory (Childs \& Williams, 1997), some basic premises of Western scientific paradigms came under scrutiny (Cohen \& Cohen, 2015). Tourism studies have been a late arrival to the Eurocentrism consideration, which started here only in the last decade. Eurocentrism was also recognized in the power relations of the tourism academia itself, alongside other tilted variables such as gender, social class, and race, where gatekeepers are still mostly "grounded in the Western Anglo-centric regions epistemic research traditions” (Ren, Pritchard, \& Morgen, 2010, p. 887).

The dominance of research from the "developed world" thus tends to perpetuate "Eurocentric" knowledge production in tourism (Tribe, Xiao, \& Chambers, 2012). Postcolonialism (Hall \& Tucker, 2004 ) is a next phase in this discussion. The mentality that goes with it has persisted, until our days and certainly in tourism. This whole mental development can be best understood by referring to Edward Said's Orientalism (1978).

In the 18th and 19th century, orientalism referred to (a) works of the "orientalist" dealing with languages and literatures of the Orient, Turkey, Syria, Palestine, Mesopotamia, and Arabia, later also India,
China, Japan, and even the whole of Asia (Macfie, 2000), and (b) specific features and styles associated with "the East." By the end of the World War II, Orientalism became a heavily charged concept and referred to a corporate institution designed for dealing with the Orient, a partial view of Islam, an instrument of Western imperialism, a style of thought based on an ontological and epistemological distinction between orient and occident, justifying and accounting for the subjugation of blacks, Palestinian Arabs, women, and many other supposedly deprived groups and people (Macfie, 2000).

In recent years, a growing critique has been provoked of an allegedly dominant "Eurocentric," "postcolonial" perspective in the prevailing paradigmatic approaches and theories in the study of tourism. Aitchison (2001), for example, pointed towards the need for gender equality, where this is much of the current debates on TRINET nowadays. Coles, Hall, and Duval (2006) suggested that the field would benefit greatly from postdisciplinarily outlook. In the sense that they would go for new directions, new discourses, "critical tourism scholarship” (Winter, 2009) reorientations, and alternatives "beyond disciplines, which is more problem focused, based on more flexible modes of knowledge production, plurality, synthesis, and synergy" (p. 293). It is also increasingly accepted within the tourism academy that our existing knowledge about tourism is "Eurocentric" and therefore disregards those knowledges that arise from other cultures and indeed from marginalized groups (Hollinshead, 1992, 2013; Platenkamp \& Botterill, 2013; Teo \& Leong, 2006; Tribe, 2006, 2007; Whittaker, 1999). A relevant example of this marginalized group was on how academics concealed their positions of neutrality just before the 86th annual tourism conference of the Organization for Economic Cooperation and Development (OECD), October 2010 in Jerusalem, by analyzing the relatively high amount of e-mail reactions on TRINET to a Palestinian tourism scholar who called for support from the tourism academic community for the rejection of Jerusalem as the place where the conference will be held. Based on this material, three categories of reactions were introduced and organized as a normative, critical discussion. In this discourse, an emancipatory perspective on this topic was presented. This emancipatory knowledge gave a 
voice to the marginalized and less heard voices in this region. With these voices a counter discourse was organized in which Arendt's “agora” (1958) was introduced as a place of plural discussions. The intention of this revitalized critical discussion was to create a climate of broader enlightenment that ultimately goes beyond the perspectives of individual parties (Isaac, Platenkamp, \& akmak, 2012). Exceptions have emerged particularly from scholars aligned closely to the critical tradition. Such academics have offered challenging political contributions, including self-reflection in relation to the production of knowledge in the social sciences (e.g., Jamal \& Hollinshead 2001; Tribe 1997, 2006) and concerns of the marginalized addressed in scholarship (e.g., Higgins-Desbiolles, 2007; Wearing, Wearing, \& McDonald, 2010).

As Chambers and Buzinde (2015) state, "we have noted, somewhat worryingly, that the critical tourism voices emanate primarily from Western scholars and it is not yet readily apparent that there is engagement with indigenous and local peoples and epistemological in the co-creation of tourism knowledge” (p. 2). It is therefore evident, despite of the above-mentioned advances in tourism research and scholarship, our knowledge about tourism is still predominantly "colonial," that there is still a privileging of Western epistemologies (Chambers \& Buzinde, 2015). Hollinshead (2013) has likewise argued for the "decolonization” of tourism studies' conceptual vocabulary as he indicates that it is still colonized in two respects:

First it tends to be the product of the disciplines that have traditionally influenced thinking on tourism. ... Second, our conceptualizations of tourism tend to be overly informed by the cosmologies of the societies from which tourism scholars have traditionally hailed-what we might clumsily call "Western" ways of understanding the world. (cited in Chambers \& Buzinde, 2015, p. 3)

Hollinshead (2014) talks about decolonization of the tourism field through "conceptual cleansing” of the existing tourism field, in order to make room for an improved conversation with the world in which colonized population can speak for their own found interest. Chambers (2014) continues the discussion and states "decolonization" implies change in both the terms and content of this conversation with the world in order to open up non-Western spaces of tourism discussions. So, the fundamental question here is how to organize this conversation without colonial influences?

In the same vein, Dann (2011) stated in his article "Anglophone Hegemony in Tourism Studies" that "tourism studies in general and the sociology in particular, like many other applied fields in the social sciences is disproportionally over-represented by one language group, namely the narrow world of English speakers" (p. 1). The tourism academia functions within the limits of power constellations of global tourism. Language is an important factor in this context. Language perspectives go far beyond language alone. Speaking and writing in English in addition implies the domination of the Anglo-Saxon academic culture. Furthermore, English as a prominent lingua franca for international tourism studies and facilitates because of this a much more universal discussion (Platenkamp, 2015).

Isaac and Platenkamp (2012) state:

Mode 3 knowledge is connected to the "slow questions" that try to deal with sickness, death, repression, but in addition to the moral virtues, as compassion, inner strengths or wisdom and other sources of existential fulfilments that remain crucial for all generations in various places. (p. 174)

Isaac, Platenkamp, Higgins-Desbiolles, and Hall (2016) state:

In a "global village" there is a need for plural discussions on values and norms. This implies that a plural concerto of various transcendent values and perspectives from all over the globe has to be organized in the tension between self and other. One has to live with differences and try to understand them. Simultaneously there is no escape from them. (p. 246)

How does the tourism academy integrate different cultures into this lingua franca in order to include as much as possible the richness of the other cultural perspectives? How to approach the international academy with all these differences in power balance on one hand, and the urge to create an international academia on the other? How to challenge academics from diverse backgrounds to use the richness of their own traditions and translate 
that knowledge into the international tourism discourses (Isaac et al., 2016)? How to decenter the Anglo-Saxon hegemony where using English as the lingua franca?

This special issue contains a series of articles that capture just a taste of the types of cutting-edge thinking and research in the domain of science and power relations in tourism studies. We hope that in reading this volume scholars will be inspired to commence their own studies that will meaningfully advance this body of research.

Selwyn, in his article "The Rise and Fall of Orientalism in Travel, Tourism, and Cultural Production: Report From Palestine/Israel,” offers a very cogent summary of Orientalism and postcolonialism through using a traveler's eye, revisits some of the foundational aspects of Orientalism in geographically and theoretically general terms and the geographical focus narrows to Palestine/ Israel, simultaneously allowing and leading to a subsequent rewidening of the theoretical focus. Some examples of contemporary tourism initiatives bearing on Orientalism are given. At this point, Said's (1978) view that "enough is being done in the human sciences to provide the contemporary scholar with insights, methods, and ideas that could dispense with racial, ideological, and imperialist stereotypes" (p. 328) is recalled in order to advance the argument that these examples of work in the travel, tourism, and pilgrimage field actually constitute a stream of resistance to orientalist thinking.

The second article focuses on Shangri-La County in Diqing Tibetan Autonomous Prefecture in Southwest China. In this article, Zhang makes an attempt to look into the contents and contexts of the recent "reflexive calls" in tourism studies and social research in general. Through critically questioning what "reflexivity" is and what context it has been applied, she argues that both the researcher and the researched subjects are a mixture of "selves," and they both go through the process of interpreting information and thus always attempt to negotiate with their surroundings. Therefore, she argues that we must rethink the current normalized ideas of "reflexivity" in social research to examine/self-examine the researcher's intention or actual capacity to practice "reflexivity."

Ivanova, in her work "The Inclusion of the Communist/Socialist Heritage in the Emerging
Representations of Eastern Europe: The Case of Bulgaria," brings us into domain of power, identity, and heritage. Specifically, she tackles the role of communist/socialist heritage in the contemporary Bulgarian identity and the ways communist heritage has been included/excluded from representations of Bulgaria. Ivanova argues that heritage is a political matter and the question is who has the power to represent or suppress the certain heritages and past. Further, she asserts that tourism has played an important role in the creation and normalization of the new European identity and the silencing of the socialist past of the country. This work touches on the adaptive function of heritage despite its contradicting visions and images as long as they are easy to read by the tourism industry. It helps us to understand some of the politics of heritage in the extant literature, like the suppression and marginalization of the past, even destruction of the perceived heritage, a symbolic rejection of the ideas of past.

This sort of integrative thinking is also captured in Ahmad's article "Power Struggles Within and Between Organizations in Tourism Business: A Bourdieusean Approach to Organizational Analysis," though this time an effort to elicit new insights that Bourdieu's sociological paradigm may bring to organizational analysis in tourism. This article seeks to examine and explain contestations for domination within and between travel agencies within the framework of Bourdieu's relational analysis, using his theoretical triad: capital, habitus, and field. Examining contestations at the individual level (capital and dispositions), the mesolevel (habitus), and at the macrolevel (field) within and between travel companies, the article proposes to investigate organizational practices and strategies within and between travel companies. It argues that organizational practices such as those of maximizing the distinction between tourist and traveler, and overwhelming promotion of ecotourism and "authenticity," and emergence of boutique travel agencies and hotels can practically be explained within the contours of Bourdieu's relational analysis. Drawing empirical evidence from travel companies, this article, through archival research and analogical theorizing, also proposes that organizational members import capital and habitus from their previous fields of struggle, from the social and professional 
arenas of their past to organizational fields to form and shape organizational habitus.

The final article by Hollinshead and Suleman draws from the work of recent commentators in Tourism Studies like Coles, Hall, and Duval (calling for much more prevalent adisciplinary/extradisciplinary cognition in Tourism Studies), like Franklin (demanding much more commonplace critique of the ways in which different societies are ordered), and like Hollinshead (bemoaning the general absence of open-to-the-future research agendas in and across the field). The article aims to consolidate the advances signposted by such new wave/new sense social theorists by drawing up a substantial conceptual glossary to help Tourism Studies researchers (and investigators in related fields) towards improved identification about the cosmologies of "other," "distant," or "underrecognized" populations, and towards more pertinent research agendas into the cosmologies and aspirations of "different" peoples.

\section{References}

Aitchison, C. (2001). Gender and leisure research: The codification of knowledge. Leisure Sciences, 23(1), 1-19.

Arendt, H. (1958). The human condition. Chicago, IL: The University of Chicago Press.

Chambers, D. (2014). Tourism studies and epistemological decolonization. Paper presented at the International Sociologist Association conference, Research Committee 50 on International Tourism, July15-18, Yokohama, Japan.

Chambers, D., \& Buzinde, C. (2015). Tourism and decolonisation: Locating research and self. Annals of Tourism Research, 51, 1-16.

Childs, P., \& Williams, R. J. P. (1997). An introduction to post-colonial theory. New York: Prentice-Hall.

Coles, T., Hall, C. M., \& Duval, D. T. (2006). Tourism and post-disciplinary enquiry. Current Issues in Tourism, 9(4-5), 293-319.

Cohen, E., \& Cohen, S. A. (2015). Beyond Eurocentrism in tourism: A paradigm shift to mobilities. Tourism Recreation Research, 40(2), 157-168.

Dann, G. (2011). Anglophone hegemony in tourism studies today. Enlightening Tourism: A Pathmaking Journal, 1(1), 1-30.

Foucault, M. (1966). Les mots et les choses. Paris: Gallimard.

Hall, M., \& Tucker, H. (Eds.). (2004). Tourism and postcolonialism: Contested discourses, identities and representations. London: Routledge.

Higgins-Desbiolles, F. (2007). Hostile meeting grounds: Encounters between the wretched of the earth and the tourist through tourism and terrorism in the 21st century. Hong Kong: The Ecumenical Coalition on Tourism.
Hollinshead, K. (1992). "White gaze," "red people"shadow visions: The disindetification of "Indians" in cultural tourism. Leisure Studies, 11, 43-64.

Hollinshead, K. (2013). Speaking of tourism part II: The ongoing development of a conceptual glossary on fantasamatic. Paper presented at the Tourism in a PostDisciplinary Era Conference, June 19-22, Neuchatel, Switzerland.

Hollinshead, K. (2014). Tourism studies and conceptual unsettlement: The decolonisation of the bleached field. Paper presented at the International Sociologist Association Conference, Research Committee 50 on International Tourism, July15-18, Yokohama, Japan.

Isaac, R. K. (2016). Eurocentrism tourism. In J. Jafari \& H. Xiao (Eds.), Encyclopedia of tourism (pp. 1-2). New York: Springer.

Isaac, R. K., \& Platenkamp, V. (2012). Ethnography of hope in extreme places: Arendt's agora in controversial tourism destinations. Tourism, Culture and Communication, 12, 173-186.

Isaac, R. K., Platenkamp, V., \& akmak, E. (2012). Message from paradise. A critical reflection on the tourism academy in Jerusalem. Tourism, Culture and Communication, 12, 159-171.

Isaac, R. K., Platenkamp, V., Higgins-Desbiolles, F., \& Hall, C. M. (2016). Giving Palestinian tourism(s) a voice. In R. Isaac, C. M. Hall, \& F. Higgins-Desbiolles (Eds.), The politics and power of tourism in Palestine (pp. 244-249). London: Routledge.

Jamal, T., \& Hollinshead, K. (2001). Tourism and the forbidden zone: The underserved power of qualitative inquiry. Tourism Management, 22, 63-82.

Jorn, R. (2004). How to overcome ethnocentrism: Approaches to culture of recognition by history in the twenty-first century. History and Theory: Studies in the Philosophy of History, 43, 118-129.

Kuhn, T. S. (1962). The structure of scientific revolutions. Chicago, IL: The University of Chicago Press.

Lakatos, I., \& Musgrave, M. (1970). Criticism and the growth of knowledge. Cambridge, UK: Cambridge University Press.

Macfie, A. L. (2000). Introduction. In A. L. Macfie (Ed.), Orientalism: A reader (pp. 1-8). New York: New York University Press

Platenkamp, V. (2015). Academic insulae: The search for a paradigm in and for tourism studies. Tourism Analysis, 20, 561-571.

Platenkamp, V., \& Botterill, D. (2013). Critical realism, rationality and tourism knowledge. Annals of Tourism Research, 41, 110-129.

Popper, K. R. (1963). Science: Problems, aims and responsibilities. Federal Proceedings, 22, 961-972.

Popper, K. R. (1972). Objective knowledge. London: Routledge and Kegan Paul.

Ren, C., Pritchard, A., \& Morgan, N. (2010). Constructing tourism research: A critical inquiry. Annals of Tourism Research, 37(4), 885-904.

Said, E. (1978). Orientalism. New York: Random House. 
Teo, P., \& Leong, S. (2006). A postcolonial analysis of backpacking. Annals of Tourism Research, 33(1), 109-131.

Tribe, J. (1997). The indiscipline of tourism, Annals of Tourism Research, 24(3), 638-657.

Tribe, J. (2006). The truth about tourism. Annals of Tourism Research, 33(2), 360-381.

Tribe, J. (2007). Critical tourism: Rules and resistance. In I. Ateljevic, A. Pritchard, \& N. Morgan (Eds.), The critical turn in tourism studies (pp. 504-520). London: Sage.

Tribe, J., Xiao, H., \& Chambers, D. (2012). The reflexive journal: Inside the black box. Annals of Tourism Research, 39(1), 7-35.
Wallerstein, I. (1997). Eurocentrism and its avatars. New Left Review, 226, 39-108.

Wearing, S. L., Wearing, M., \& McDonald, M. (2010). Understanding local power and interactional processes in sustainable tourism: Exploring village-tour operator relations on the Kokoda Track, Papua New Guinea, Journal of Sustainable Tourism, 10(1), 61-76.

Whittaker, E. (1999). Indigenous tourism: Reclaiming knowledge, culture and intellectual property in Australia. In M. Robinson \& P. Boniface (Eds.), Tourism and cultural conflicts (pp. 33-45). Wallingford: CABI.

Winter, T. (2009). Asian tourism and the retreat of AngloWestern centrism in the tourism theory. Current Issues in Tourism, 12(1), 21-31. 